\title{
APRESENTAÇÃO DO PROCESSO DE RECONHECI- MENTO DO LAÇO COMO ESPORTE E PATRIMÔNIO CULTURAL IMATERIAL, POR MEIO DE LEI
}

\author{
Presentation of process of recognition of the tie-down-roping with \\ sport and Immaterial Cultural Heritage, by means of law
}

\section{Eduardo Fonseca Alves}

Laçador. Pesquisador da Temática Laço. Profissional do Agronegócio. Idealizador e Diretor Cultural da Federação Gaúcha de Laço - FGL (Porto Alegre, RS, Brasil).

\section{Mário Antônio Taddei Sá}

Mestre em Educação pela Universidade Luterana do Brasil. Especialista em Supervisão pela Educacional Faculdades Porto-Alegrenses - FAPA. Graduado em Filosofia pela Faculdade de Filosofia Nossa Senhora de Imaculada Conceição. Coordenador dos Cursos de Pós-graduação do Complexo de Ensino Superior de Cachoeirinha/Brasil (Cesuca).

\begin{abstract}
Resumo
O presente artigo trata do processo que levou ao reconhecimento das provas de Laço como patrimônio cultural imaterial, por meio de lei. Durante mais dez anos, defendeu-se que uma prova campeira, recriada na forma de desporto, poderia ser reconhecida como Patrimônio Cultural Imaterial, o que se confirmou em 2017, quando a Constituição da República Federativa do Brasil passou a prever essa possibilidade de reconhecimento a práticas desportivas que envolvessem animais. $A$ referida ação teve o intuito de valorizar e salvaguardar as provas de Laço e foi desenvolvida sem sofisticação, algo compatível com a produção de coisas simples, como as tradições. Sendo assim, será apresentado um resumo do que possibilitou que as referidas provas, incluindo as esportivas, fossem declaradas, por meio de Lei, como Patrimônio Cultural Imaterial do Brasil e do Estado do Rio Grande do Sul. O trabalho desenvolvido representou um laboratório que levou à comprovação de que o reconhecimento por lei é um alternativa viável e resulta de uma demanda que pode ser acolhida pelo Legislativo, o qual legitimará a anuência não só da comunidade produtora, mas da sociedade, já que, no processo democrático, a maioria, através de seus representantes, proporciona a consolidação dos conceitos e diretrizes.
\end{abstract}

Palavras-chave: Patrimônio cultural. Processo. Reconhecimento e lei.

\section{Abstract}

This article deals with the process, which led to the recognition of the tie-down-roping competitions ("provas de Laço") as Immaterial Cultural Heritage, by means of law. During more than ten years, it has been defended that a country competition ("prova campeira"), recreated in the form of a sport, could be recognized as Immaterial Cultural Heritage, which was confirmed in 2017, when Constitution of the Federative Republic of Brazil started accepting this possibility of recognition to the sportive practices involving animals. The referred action has had the objective of valuing and safeguarding the tie-down-roping competitions ("provas de Laço), which was developed without sophistication, something compatible with the production of simple things, such as traditions. Therefore, a summary on what made the referred tie-down-roping competitions ("provas de Laço"), including the sportive ones will be presented on how they became possible as well as were declared by the means of Law, as Immaterial Cultural Heritage of Brazil and the State of Rio Grande do Sul. This developed final paper has represented a laboratory which led to the evidence that the recognition by the Law is a viable alternative and results from a demand that may be accepted by the Legislative, which will legitimize the consent, not only from the producing community, but also the society, whereas in the democratic process, the majority, through their representatives, provides the consolidation of concepts and guidelines.

Keywords: Cultural heritage. Process. Recognition and law. 


\section{Sumário}

1. Introdução; 1.1 Breve histórico da proposta; 2. Método para construção da proposta para reconhecimento de Patrimônio Imaterial, por meio de Lei; 2.1 Pesquisa, articulação e consulta das partes envolvidas; 2.2 Análise conceitual; 2.3 Histórico da prática, enquadramento no conceito, anuência e apresentação da proposta de reconhecimento; 3 . Resultados; 4. Conclusão; 5. Notas; Referências

\section{INTRODUÇÃO}

O reconhecimento do Laço como Patrimônio Cultural Imaterial, por meio de Lei respaldada pela Constituição da República, comprova a viabilidade do processo a ser apresentado a seguir. Sendo assim, o que será relatado, baseado em evidências, pode ser visto como um laboratório que levou à criação de uma base para um possível método alternativo, que visa ao reconhecimento de patrimônios culturais.

Nesse sentido, será relatada a história da proposta que visou obter o reconhecimento do Laço como esporte e patrimônio imaterial, a qual deu origem ao processo a ser apresentado.

\subsection{BREVE HISTÓRICO DA PROPOSTA}

Surgida em 2007, a proposta de reconhecimento do Laço como Patrimônio Cultural Imaterial foi apresentada ao Governo do Estado do Rio Grande do Sul naquele ano. No ano seguinte, a mesma apresentação foi realizada no Congresso realizado pelo Movimento Tradicionalista Gaúcho - MTG. O trabalho contou com consultas ao Instituto do Patrimônio Histórico e Artístico Nacional - IPHAN, realizadas por um período de aproximadamente 10 anos, bem como ao Ministério dos Esportes. Recentemente, ganhou força com a fundação da Federação Gaúcha de Laço - FGL, em 2013.

No ano de 2016, a comunidade produtora da Vaquejada, dos Rodeios, do Laço e de outras tantas provas que envolvem animais intensificou as ações por conta das ameaças que poderiam levar ao fim desse tipo de manifestação cultural. Nesse contexto, então, surgiu a Lei Federal 13.364, que elevou as provas de Laço à condição de manifestação cultural nacional e de Patrimônio Cultural Imaterial. No ano seguinte, em 2017, a partir do Projeto de Emenda Constitucional - PEC304, a Constituição da República Federativa do Brasil passou a prever práticas desportivas que utilizem animais como patrimônio cultural imaterial. Por fim, em 2018, a Lei Estadual 15.244 declarou a prova de laço como bem integrante do patrimônio cultural imaterial do Estado do Rio Grande do Sul, considerando-a, também, como atividade esportiva.

Este trabalho, portanto, apresentará, além dessa sequência de acontecimentos, um procedimento alternativo que pode ser utilizado por outras comunidades produtoras de manifestações culturais que almejem um reconhecimento dessa ordem.

\section{MÉTODO PARA CONSTRUÇÃO DA PROPOSTA PARA RECONHECIMENTO DE PATRIMÔNIO IMATERIAL, POR MEIO DE LEI}

\subsection{PESQUISA, ARTICULAÇÃO E CONSULTA DAS PARTES ENVOLVIDAS}


Para dar início ao processo de reconhecimento do Laço como Patrimônio Cultural Imaterial, houve a necessidade de articulação no Rio Grande do Sul, o que contou com o empenho de um membro da comunidade produtora da manifestação cultural Laço, o qual, em 2007, tomou a iniciativa de defender o entendimento de que uma prática campeira recriada na forma de esporte poderia ser patrimônio imaterial. A partir disso, desenvolveu o trabalho de pesquisa sem sofisticação, o que era de se esperar, já que a produção de tradições é caracterizada pela transmissão de saberes por meio da oralidade, algo que remete à simplicidade e a pessoas simples. Nesse contexto, que foi o ponto de partida, pode-se dizer que o indivíduo, pesquisando e provocando a reflexão com possíveis interessados, passou a tentar "fazer a leitura do mundo que o rodeia de forma que o levasse à compreensão do universo sociocultural e da trajetória histórico-temporal em que estava inserido", 1 agindo em conformidade com o entendimento de Horta (201-?), apresentado no "Guia Básico da Educação Patrimonial".

A busca de um reconhecimento nessa linha exige um mergulho na temática, sendo que nem todos estão dispostos a tomar a iniciativa e se enfronhar no assunto. Por isso, nada mais natural do que o surgimento de uma liderança que se envolva com a busca de informações e com a articulação. Poderia ser o presidente de uma associação civil, parte legítima para provocar a instauração de processo segundo prevê o Decreto 2551/2000. ${ }^{2}$ Porém, nesse caso, tratava-se de um laçador, ou seja, um verdadeiro detentor do saber que dá origem a essa tradição.

Dentro de um comportamento que parece ser compatível com os métodos de Educação Patrimonial apresentados por Horta, ${ }^{3}$ a iniciativa ia em direção à apropriação consciente do seu Patrimônio, fator indispensável no processo de preservação sustentável desses bens, assim como no fortalecimento dos sentimentos de identidade e cidadania. Nessa linha, surgia a iniciativa que visava ao reconhecimento do Laço como patrimônio cultural imaterial e, também, como esporte.

O empenho em tentar entender o que era produzido para passar isso ao restante da comunidade produtora pode ser entendido não só como articulação, mas como uma atitude de cidadania por parte do membro da comunidade produtora, que passou a defender o bem. Articular com as partes interessadas é inevitável e é disso que virá a anuência, sendo que o histórico demonstrará que não há necessidade de unanimidade para se obter um reconhecimento dessa ordem.

$\mathrm{Na}$ apresentação das propostas, a busca ocorreu de forma independente, ou seja, por meio de procedimentos distintos que envolveram consultas a órgãos diferentes, que procederam independentemente, já que eram dois processos: um, que envolvia obter o reconhecimento como desporto, e o outro, que tratava do reconhecimento como patrimônio cultural imaterial. Porém, no desenrolar das ações, vislumbrou-se a possibilidade de reconhecer que uma prática desportiva pode ser patrimônio cultural imaterial, o que ensejou uma análise que desconsiderava dicotomia, já que, ao ser considerado um esporte, o bem imaterial não deixaria de ser cultura. Então, acreditou-se que o Laço poderia ser uma manifestação cultural em forma de esporte, resultante de um processo de tradição. 
Assim, foram feitas consultas a diversos órgãos, provocando os possíveis envolvidos com a temática: IPHAN, IPHAE, Secretaria Estadual de Cultura, Ministério dos Esportes, Secretaria Estadual de Esportes, Secretaria Municipal de Cultura, MTG, FIGTF, CBTG, OAB, Assembleia Legislativa, além de universidades e especialistas na área. Os diversos posicionamentos que resultaram da provocação, possibilitaram um melhor entendimento para definição de como proceder de forma a atingir os objetivos estabelecidos que, em muito, dependiam de posicionamentos de parte dos relacionados.

As ações para obter o reconhecimento envolveram pesquisas básicas por meio das quais se buscou conhecer os conceitos de patrimônio imaterial e de esporte, de forma obter subsídios para gerar a reflexão e apreciação por parte de especialistas e de agentes competentes para efetivação dos objetivos das propostas, entre eles, deputados. Esse procedimento gerou a comunicação e a interação entre a comunidade e os agentes responsáveis pela preservação e estudo dos bens culturais, possibilitando a troca de conhecimentos e a formação de parcerias para a proteção e valorização do bem, o que, segundo Horta, ${ }^{4}$ faz parte da educação patrimonial. Assim, a Federação Gaúcha de Laço - FGL, fundada por Cleber Quadros Vieira, foi um dos meios de formar parceria e dar legitimidade às manifestações da comunidade produtora perante os Poderes Executivo e Legislativo. A referida entidade tornou-se um meio de reunir pessoas interessadas na causa, sendo, conforme previsto no Inciso IV, do Art. $2^{\circ}$, do Decreto $3551 / 2000,{ }^{5}$ parte legítima para provocar a instauração do processo de registro do bem cultural, por ser uma associação civil. Além disso, há de se considerar que, segundo o §2o do Art. 40, da Lei Federal 9.615/98, a organização desportiva do País, fundada na liberdade de associação, integra o patrimônio cultural brasileiro. Logo a Federação tem mais esse respaldo.

O reconhecimento do Laço como patrimônio cultural imaterial foi pleiteado por meio de Lei paralelamente à busca do registro junto ao Instituto do Patrimônio Histórico e Artístico Nacional - IPHAN. Nesse processo, foram utilizados como parâmetro: as diretrizes contidas na Resolução 001/2006, do IPHAN, bem como pareceres de patrimônios já reconhecidos pelo Instituto; a Convenção para a Salvaguarda do Patrimônio Cultural Imaterial da UNESCO; e, por fim, o já referido Decreto 3551/2000. Então, foi por meio desses documentos que se obteve conhecimento dos conceitos de patrimônio cultural imaterial e dos procedimentos para obter o reconhecimento.

O procedimento via IPHAN envolve, basicamente, o enquadramento no conceito, a obtenção de documentos históricos, a anuência da comunidade produtora e a apresentação da proposta por parte legítima, o que foi feito na busca do reconhecimento por meio de lei. Porém, nas interpretações, não houve sofisticação e complexidade, mas objetividade e pontualidade dentro dos limites de conhecimento dos simples produtores de tradições, que se imagina não serem eruditos, pelo menos na grande maioria. O processo foi baseado em evidências, facilitando o entendimento por parte da comunidade produtora e das partes interessadas.

\subsection{ANÁLISE CONCEITUAL}

A análise conceitual de Patrimônio Imaterial ocorreu de forma objetiva, o que é plau- 
sível, nesses casos, já que não se pode esperar um entendimento muito refinado por parte de pessoas que transmitem seus saberes por meio da oralidade. Se formos esperar sofisticação na análise por parte dos produtores, muito provavelmente diversos patrimônios nunca serão identificados e reconhecidos. Nessa linha, o trabalho foi iniciado buscando verificar se o reconhecimento pleiteado se enquadrava no conceito a seguir:

\begin{abstract}
CONSIDERANDO que se entende por bem cultural de natureza imaterial as criações culturais de caráter dinâmico e processual, fundadas na tradição e manifestadas por indivíduos ou grupos de indivíduos como expressão de sua identidade cultural e social;

CONSIDERANDO que, para os efeitos desta Resolução, toma-se tradição no seu sentido etimológico de "dizer através do tempo", significando práticas produtivas, rituais e simbólicas que são constantemente reiteradas, transformadas e atualizadas, mantendo, para o grupo, um vínculo do presente com o seu passado. $^{6}$
\end{abstract}

Conforme pode ser observado, basicamente trata-se de uma criação cultural de caráter dinâmico e processual, fundada na tradição. Também é possível verificar que o ponto central para o entendimento do conceito e a identificação do bem na contemporaneidade é a ciência de que estão previstas transformações ao longo da história, motivo mais plausível para necessidade de informações históricas, na forma de documentos, produções literárias e outras fontes. A questão é que o fato de um bem imaterial ser transformado remete a matrizes que se referem ao o passado ou ao início da História. Já as recriações representam o presente, espaço temporal em que continuam acontecendo.

\title{
2.3 HISTÓRICO DA PRÁTICA, ENQUADRAMENTO NO CONCEITO, ANUÊNCIA E APRESENTAÇÃO DA PROPOSTA DE RECONHECIMENTO
}

A história da prática encontrada, a ser relatada a seguir, inicia pela verificação de que se trata de uma tradição e, que esse entendimento já existe há mais de um Século.

O patrimônio imaterial, conforme o IPHAN, está fundado na tradição, logo envolve um processo caracterizado pela transmissão por meio da oralidade, algo simples, sem requintes, nem sofisticação. Sendo assim, a verificação da legitimidade não depende somente de produções literárias, ou de documentos oriundos de procedimentos científicos, mas da história contada pelos próprios produtores das manifestações culturais. No caso do Laço, porém, existe a vantagem de João Cezimbra Jacques ter registrado, na sua produção literária "Assuntos do Rio Grande do Sul", 7 editada em 1912, a ideia de uma competição de Laço com "o fim nobre de relembrar o passado".

Historicamente, o Laço já estava se configurando como uma atividade esportiva, genuinamente rio-grandense, pelo menos desde o final do século XIX, como aponta João Cezimbra Jacques em sua obra. O autor lembra a criação do "Grêmio Gaúcho" — núcleo primeiro no culto sistematizado das tradições sul-rio-grandenses - fundado em 22 de abril de 1898, em Porto Alegre. Segundo Jaques, entre os propósitos dessa sociedade, estava praticar, ao lado dos jogos importados, "exercícios de pontaria a pé ou a cavalo, guiados por um mestre, com o Laço e com as boleadeiras, em alvos apropriados", 8 citando como exemplo, os palanques onde ganharia quem maior número de pontos tivesse por ter acertado mais vezes o alvo. Essa competição tinha a finalidade de relembrar o passado, ou seja, de 
manter vivas tradições características do Rio Grande do Sul. Logo, está evidente tratar-se de uma criação cultural fundada na tradição, o que pode ser observado na transcrição que segue, a qual, por si só, representa uma evidência, uma sustentação histórica incontestável, com mais de um século de existência.

\begin{abstract}
Ainda nos achamos em um regime em que predomina mais a indústria pastoril no nosso Estado, e desta sorte, quando menos a cultura de tais exercícios com estes dois instrumentos gauchescos - o "laço" e as "bolas" não fosse com o fim nobre de relembrar o passado, ainda não é toda via tempo de encolher o "laço" em rodilhas e de atar as sogas das "bolas" para guardá-los, porque na dita indústria os métodos tais como o dos "bretes" para marcar e beneficiar o gado vacum e cavalar, e o enfileiramento ou alinhamento sobre o "laço", estirado para pegar os cavalos, ainda não são de todo praticáveis, para que se possa dispensar totalmente o uso de tais instrumentos - isto é , - o laço e as bolas.

E depois disto se atendermos que a vida se dificulta de dia a dia e que não podemos prever o dia de amanhã, que aquele que hoje vive de uma indústria ou de uma profissão urbana não está isento de amanhã ter de abraçar uma profissão ou indústria rural, e como saber não ocupa lugar, nunca é demais sabermos exercícios característicos da nossa terra, laçar e bolear; e tanto mais que eles, além de necessários, são salutares, como quase todo o exercício físico. ${ }^{9}$
\end{abstract}

Conforme consta no conceito do IPHAN, o patrimônio imaterial envolve práticas que proporcionem manter um vínculo do presente com o passado. Há mais de cem anos, Jacques já entendia que a competição de Laço teria o fim nobre de relembrar o passado, tendo afirmado que nunca é demais sabermos exercícios característicos da nossa terra, como laçar, tanto mais que eles, além de necessários, são salutares, como quase todo o exercício físico. Nessa afirmação, também é possível identificar um elo entre a prática campeira e o esporte.

No tempo presente, o modo de ensinar a laçar envolve a transmissão por meio da oralidade de um saber composto pelo procedimento para fazer a armada, pegar as rédeas e, pelo menos, por duas técnicas conhecidas, o sobrelombo e a cortada. Ocorre que a transmissão oral é muito relacionada à tradição, além de envolver um hábito inveterado, como a História demonstra ser o de laçar, pelos gaúchos.

Além da informação histórica apresentada com mais de cem anos, houve outro indício. Questionado sobre se considerava o Tiro de Laço uma tradição, o Movimento Tradicionalista Gaúcho - MTG, respondeu, em ofício, no ano de 2010, que essa instituição tem por finalidade o culto às tradições gaúchas, dentre elas, o "tiro de Laço". ${ }^{10}$

Nesse contexto histórico identificado em que Jacques foi o destaque, restou evidente que o Laço é uma criação cultural fundada na tradição. Depois de enquadrado em um dos principais pré-requisitos do conceito, verificou-se a viabilidade para o prosseguimento do processo de enquadramento.

Então, partiu-se para a fase de entender a forma contemporânea, e é nesse ponto que entram as transformações, já que as práticas são transformadas e atualizadas, mantendo, para o grupo, um vínculo do presente com o seu passado.

Segundo Karl Diem Apud Tubino, "a história do esporte é íntima da cultura humana, pois, por meio dela, se compreendem épocas e povos."11 O Laço chegou na contemporaneidade sendo entendido e promovido pelo Movimento Tradicionalista Gaúcho apenas 
como cultura, com restrições desnecessárias à recriação na forma de esporte, se levado em consideração o entendimento de Barbosa Lessa no tocante ao tradicionalismo através da atividade recreativa ou esportiva que o caracteriza - sempre realçando os motivos tradicionais do Rio Grande do Sul - procurar mais que tudo, reforçar o núcleo da cultura rio-grandense. ${ }^{12}$ Luiz Carlos Barbosa Lessa fez parte do grupo dos 8 que iniciou o MTG, escreveu dezenas de livros e foi uma da mentes tradicionalistas brilhantes e como pode ser observado considerava o esporte parte do tradicionalismo. Já a Federação Gaúcha de Laço - FGL promove o laço como atividade esportiva e cultural, possibilitando a reiteração da prática e a manutenção da tradição. Importante frisar, que, como se observou, o Laço não deixou de ser entendido como uma tradição na contemporaneidade por nenhuma das entidades, independente das formas de entendimento no tocante ao modo de produzi-lo.

O entendimento da FGL referente a produzir o Laço como atividade esportiva e cultural - resultado de transformação - está de acordo com a forma como o IPHAN analisou a Capoeira, pois ocorreu o mesmo com esse patrimônio originado da cultura Afro, que é registrado pelo Instituto. Conforme pode ser verificado no Parecer No 031 (Registro da Capoeira como Patrimônio Cultural do Brasil), consta que a capoeira teve o mercado internacional aberto como show e como prática esportiva e cultural. ${ }^{13}$ Esse entendimento está registrado no subtítulo "Da Bahia para a roda do mundo: a capoeira na contemporaneidade", o que também demonstra ser importante entender as formas contemporâneas do Laço. Esse cenário será analisado a partir desta fase em que se discorrerá sobre o histórico.

Verificou-se que a história do Laço envolve um processo evolutivo, o que era de se esperar, depois de conhecer o conceito de patrimônio imaterial do IPHAN e da UNESCO. A evolução está atrelada a transformações a partir de matrizes, tendo sido elas que possibilitaram a sua reiteração, o que torna necessário apresentá-las no histórico. Consultando os documentos do referido Instituto, foi possível verificar que, inclusive, o Frevo e o Samba possuem mais de uma matriz.

O histórico aponta para a prática campeira do Laço, vinculada à pecuária, associada ao gaúcho e a sua história, como matriz das recriações, logo, das competições de Laço. No Volume 1 da "História Geral do Rio Grande do Sul, Colônia", é possível observar que o tipo social gaúcho surgiu da vida no campo e das lides na pecuária, sendo que o contato com a natureza e a luta pela sua sobrevivência fez dele um homem forte e enérgico acostumado ao uso do Laço e do facão. ${ }^{14}$

$\mathrm{Na}$ mesma obra, verifica-se que os historiadores argentinos preferem relacionar a origem do tipo social acostumado com o uso do laço aos primeiros povoadores de Santa Fé, cidade fundada em 1573, pelos espanhóis. Assim os colonizadores teriam constituído famílias com as nativas e tido filhos mestiços que se distanciaram da sociedade Espanhola matriz e tornaram-se criollos livres e pobres dominados gaúchos. ${ }^{15}$

Eles eram contratados para as vacarias ou se organizavam autonomamente para a caça do gado que era contrabandeado, na maioria das vezes. Diante dessa informação, pode-se dizer que esse tipo social oriundo do pampa está intimamente ligado à pecuária e ao Laço. 
Quase três séculos depois da época do surgimento do gaúcho, homem forte e enérgico acostumado com o uso do Laço e ligado à caça ao gado, Hermann Rudoldf Wendroth, ${ }^{16}$ artista plástico alemão que veio para o sul do Brasil em 1851, fez um trabalho em aquarela sobre o Rio Grande do Sul em 1852, dando o título de "Caçada ao Boi" a uma de suas gravuras.

Segundo Nicolau Dreys, que escreveu no século XIX, independente das armas comuns aos militares de todos os países, o rio-grandense trazia consigo duas armas auxiliares que lhe eram peculiares e que somente os homens desta parte da América sabiam manejar com habilidade, sendo o Laço uma delas. ${ }^{17}$

Na sequência histórica, a prática é recriada por João Cezimbra Jacques, na forma de competição, por volta do início do Século XX. Logo, a configuração atual da competição disseminada pelo Brasil é resultado da técnica de contenção em que se utilizava o Laço no campo, apesar de ter sido associada à caça e à guerra.

$\mathrm{Na}$ fase em que foi transformada em competição, foram identificados pelo menos três marcos, que são vinculados às iniciativas de João Cezimbra Jaques, que a teria transformado em competição; Alfredo José dos Santos, por ter sido o criador do tiro de Laço; e José Atanásio Lemos Neto, por ter viabilizado a formalização do Laço como esporte.

Por volta do final do Século XIX e início do Século XX, João Cezimbra Jacques teve a ideia de criar uma competição de Laço e a registra em uma produção literária de sua autoria. Nesse período, também foi publicado no Jornal Diário, de 19 de setembro de 1912, o anúncio feito pelo Grêmio Gaúcho, informando aos sócios que a data de 20 de setembro seria comemorada no dia 22 do mês corrente. Na programação divulgada, estava prevista a realização do torneio de laçar uma caveira de rês ao palanque, com premiação para o melhor laçador. ${ }^{18}$

Tempos depois, ainda no início do século XX, o médico e escritor Severino Sá Brito, ${ }^{19}$ ao descrever as lides campeiras na obra "Trabalhos e Costumes dos Gaúchos", lembrava que muitos dos trabalhos da vida rural se executavam como se fossem diversões ou esportes. Dentre eles, estavam os apartes e o ato de laçar com o objetivo de capturar bovinos e conduzi-los ao rodeio. Já nessa época, é possível observar uma correlação com o desporto e a lide de laçar como matriz.

Alfredo José dos Santos surgiu com sua ideia que levou à criação do tiro de laço no início da década de cinquenta. Segundo o tradicionalista Luiz Carlos Bossle da Costa, foi em 1952, no distrito de Esmeralda, em Vacaria, hoje município, que se realizou a primeira competição de Tiro de Laço, no Rio Grande do Sul. ${ }^{20}$

O que Costa ${ }^{21}$ relata leva a entender que Alfredo teria se inspirado no futebol para criar a competição, ou seja, em um esporte. Teria ocorrido da seguinte forma: Alfredo, após recusar o convite para ser patrono de uma partida de futebol, justificando que fosse para laçar uma novilha por encomenda, iria encontrar-se com alguns amigos em uma lida com o gado. O resultado disso foi uma correlação com o futebol, de onde surgiu a competição. ${ }^{22}$ Se levada em conta a ideia registrada por João Cezimbra Jacques, em 1912, e o torneio de 
Laço na caveira realizado naquela época, o tiro de Laço criado em 1952 seria apenas mais uma recriação da competição de Laço. Lembrando, ainda, que a ideia de Jacques compôs o início do projeto tradicionalista do Rio Grande do Sul.

O Jornal do Dia, ${ }^{23}$ de Porto Alegre, relata, em reportagem publicada em maio de 1963 , o culto da tradição gaúcha em forma de competições esportivas, feitas através de torneios de Laço ou laçadas, nos municípios de Vacaria, São Francisco de Paula e Bom Jesus. Segundo a mesma fonte, esses torneios vinham sendo realizados desde 1961. Assim, temos mais um momento da História em que o Laço é associado ao esporte por conta do retorno da classificação como torneio.

Mais tarde, na década de 80, o Laço adquire o status de modalidade esportiva. Foi quando advogado e pecuarista Atanásio Neto tornou-se o primeiro presidente da Federação de Clubes de Laço do Mato Grosso do Sul, fundada em 14 de abril de 1984. ${ }^{24}$ Cabe destacar o aspecto cultural dessa recriação por meio da alínea a, do Art.4 $4^{\circ}$ do Estatuto da referida entidade, onde consta como finalidade "reunir e coordenar todas as entidades, pessoas físicas ou jurídicas que se interessam e cultuam direta ou indiretamente a Tradição Campeira e Cultural do MS." ${ }^{25}$ Naquele Estado, o Laço Comprido foi instituído esporte em 2003, por meio da Lei $2630 .{ }^{26}$

Mesmo tendo crescido como competição fora do Estado, o Laço representa um dos traços mais fortes da identidade cultural do Rio Grande do Sul, se considerada a Estátua do Laçador, instituída como patrimônio histórico e cultural e escultura-símbolo do Estado do Rio Grande do Sul, através da Lei Estadual N 12.992/2008. Cabe ressaltar que todo o patrimônio material tem seu aspecto imaterial, logo nesse caso, vislumbra-se a possibilidade da prática do Laço como tal.

Em 2004, no Rio Grande do Sul, foi sancionada pelo prefeito de Glorinha, Darci José da Lima Rosa, a Lei $n^{\circ}$. 714, que instituiu o tiro de Laço como modalidade esportiva oficial do município. ${ }^{27}$

A Federação Gaúcha de Laço - FGL foi fundada em 2013, tornando o Laço prática desportiva formal, conforme prevê a Lei $9.615 / 98$, no $\S 1^{\circ}$ do Art. $1^{\circ}$, por se tratar de uma entidade nacional de administração do desporto. ${ }^{28}$ As aprovações dos projetos apresentados pela Federação ao PRÓ-ESPORTE/RS confirmaram a condição esportiva e ainda proporcionaram recursos para o fomento das atividades. A partir desse momento, a entidade passou a capitanear uma série de projetos em defesa dos interesses da comunidade produtora do Laço.

A intensificação dos ataques dos ativistas protetores dos animais fez com que fosse acelerada a busca pelo reconhecimento como patrimônio imaterial, o que veio a ocorrer por meio da Lei Federal 13.364, em 2016, que "elevou as provas de Laço à condição de manifestação cultural nacional e de patrimônio cultural imaterial", ${ }^{29}$ deixando evidente a relevância do que estava sendo proposto nesse projeto.

Mais tarde, com a aprovação do Projeto de Emenda Constitucional - PEC 304/2017, que deu origem à Emenda Constitucional 96, a Constituição da República Federativa do 
Brasil passou a prever práticas desportivas que envolvam animais como patrimônio cultural imaterial, no $\S 7^{\circ}$ do Art. $225,{ }^{30}$ comprovando a viabilidade do que foi proposto nesse projeto, em 2007, no tocante a reconhecer o Laço como esporte e como patrimônio imaterial. Mais do que isso, representou respaldo constitucional para consolidar o Laço como atividade esportiva e cultural.

O enquadramento no conceito de patrimônio imaterial durante o levantamento histórico realizado, o qual levou em consideração as matrizes e recriações, bem como o respaldo legal construído recentemente, resultado de ações que deixaram evidente a anuência da comunidade produtora, levaram o Deputado Juvir Costella a apresentar o Projeto de Lei $144 / 17 .{ }^{31}$

Iniciativas como as que serão relatadas a seguir representaram a anuência necessária para levar a proposta adiante, na esfera estadual. Em 17 de junho de 2013, o repórter Giovani Grizotti noticiou que em Gravataí, um grupo de políticos e tradicionalistas deu início ao processo para tornar o tiro de Laço patrimônio cultural imaterial do país. ${ }^{32}$ Nesse dia, houve uma reunião na Câmara de Vereadores, no município mencionado, que contou com a presença de um número substancial de laçadores e de tradicionalistas, sendo que muitos se deslocaram a cavalo. Mas talvez a maior mobilização já vista em prol da manutenção de uma manifestação cultural - requerendo o reconhecimento de um patrimônio imaterial tenha sido a realizada em Brasília, que levou à aprovação da PEC 304. Nos dias 24 e 25 de outubro de 2016, houve um grande manifesto na capital federal, com início do deslocamento das comitivas do Parque Leão em direção à Esplanada dos Ministérios no dia 24, com término às $5 \mathrm{~h}$ do dia $25 .{ }^{33} \mathrm{~A}$ programação contou com Missa do Vaqueiro, ato público em frente ao Congresso Nacional, benção aos vaqueiros em frente à Catedral de Brasília, concentração em frente ao Congresso Nacional para Cavalgada "Vaquejada Legal", Ave Maria interpretada por artistas em homenagem aos vaqueiros e cavaleiros e, por fim, a manifestação com a apresentação de artistas que apoiaram a Vaquejada Legal. Essa ação acabou por beneficiar todas as práticas campeiras recriadas na forma de esportes.

No final de 2018, o que foi almejado aconteceu, já que o Laço foi reconhecido, por meio da Lei Estadual 15.244/2018, que o declarou como bem integrante do patrimônio cultural imaterial do Estado do Rio Grande do Sul e que considerou como atividade esportiva a prova de Laço. ${ }^{34}$

O projeto contemplou o Laço, sendo que a competição, forma possivelmente predominante em que acontece, foi recriada várias vezes. Nesse sentido, atualmente temos: Laço, Laço Esporte, Tiro de Laço, Tiro de Laço Esporte e Laço Comprido, todas provas de Laço, em conformidade com o que prevê de forma genérica o texto da Lei Federal 13.364/16. Por conta do modo de fazer a armada e do tamanho dela, bem como do jeito de pontuar, é possível afirmar que todas essas são recriações da competição surgida no Rio Grande do Sul, chamada popularmente de Laço, porém, em uma análise específica, ao que parece, somente as provas de laço esportivas reconhecidas como patrimônio imaterial que disponham de lei específica estão resguardadas e permitidas pela Constituição, já que o objeto do $\S 7^{\circ}$ do Art. 225 , são práticas desportivas que utilizem animais, o que torna ainda mais importante a forma de reconhecimento proposta desde 2007. 


\section{RESULTADOS}

Nesse processo que teve por objetivo o reconhecimento como patrimônio imaterial, por meio de lei, ressalta-se o fato de que os projetos são submetidos às Comissões do Legislativo, entre elas, a de Constituição e Justiça e de Educação, Cultura, Desporto, Ciência e Tecnologia, as quais "têm caráter técnico legislativo ou especializado que tem por fim apreciar as proposições submetidas a seu exame e fiscalização sobre elas, emitindo parecer."35 Sendo assim, depois desse reconhecimento que passou por análise técnica, em especial de uma comissão que contempla a cultura, ficou demonstrado que o IPHAN não é o único a ter legitimidade para analisar e emitir pareceres que viabilizem esse tipo de reconhecimento.

Ademais, cabe destacar que a demanda acolhida pelo Legislativo legitimou a anuência, não só da comunidade produtora, mas da sociedade, já que, no processo democrático, a maioria, através de seus representantes, - nesse caso, 35 deputados estaduais a favor, do total de $41^{36}$ - proporciona a consolidação dos conceitos e diretrizes. Se, até o momento da aprovação do projeto de lei, o que tinha sido proposto não era considerado, no sentido de não ser um procedimento previsto, a partir da sanção da Lei passou a ser legal e, portanto, deve ser respeitado, bem como passou a poder ser seguido e utilizado por outros cidadãos. Ainda, há de se considerar o fato de que essa iniciativa fez surgir um bem cultural de natureza imaterial na forma de esporte, que constitui patrimônio cultural brasileiro, mas que não se enquadra nos livros definidos até o momento, o que gera a necessidade de abertura de um novo livro de registro, algo previsto no $§ 30$ do Art. 10 do Decreto $3551 .{ }^{37}$

Houve uma fase decisiva no processo que levou ao reconhecimento das provas e do Laço como patrimônio imaterial do Brasil. Iniciou quando a proposta foi levada à Câmara, ao Senado e ao Instituto do Patrimônio Histórico e Artístico Nacional - IPHAN que, ao tomar conhecimento, manifestou-se contrário. Nessa fase, a objeção do instituto era legítima por conta de fazer parte da esfera do executivo e ser a instituição competente para fazer esse tipo de reconhecimento e, depois de votado o projeto de Lei e, aprovado pelo Legislativo, também. Porém, quando chegou ao Executivo e o Presidente da República sancionou a Lei 13.364/16, ignorando a competência do Instituto do Patrimônio Histórico e Artístico Nacional prevista no Decreto 3551/2000, esse órgão perdeu o direito de discordar. Há de se considerar que a referida Lei, bem como a PEC 304, resultou de grandes mobilizações das comunidades produtoras de manifestações culturais campeiras brasileiras, caracterizando anuência, o que deveria ter sensibilizado o IPHAN, mas não ocorreu. Portanto, um grande ganho foi conhecer um meio alternativo ao IPHAN.

As provas que ganharam uma configuração esportiva acabaram por gerar um mercado de entretenimento tipicamente gaúcho que faz parte da economia dos esportes e da cultura, logo, geram um impacto socioeconômico. Isso torna necessária a preservação de tal atividade, de modo a manter os empregos, empreendimentos e a renda gerada a partir dela, mas, principalmente, por possibilitar a manutenção de uma prática secular vinculada ao tipo social gaúcho. Isso faz parte do grande mosaico cultural brasileiro e não é menos importante do que o Samba, o Frevo, a Capoeira e outros já registrados. Logo, tal reconhecimento representa uma ação de salvaguarda, por conta da valorização proporcionada. 
As ameaças por parte dos contrários aos rodeios levaram os praticantes do Laço a se conscientizarem sobre a necessidade de obter o reconhecimento como patrimônio imaterial, de modo que passaram a atentar para a importância de criação de políticas de salvaguarda para as provas que afirmassem a relevância delas no cenário cultural, não só regional e gaúcho, mas nacional. Então, a busca pelo reconhecimento gerou um despertar no tocante à criação de defesas no campo intelectual.

O reconhecimento da importância da tradição do Laço reforçou as bases da cultura rural em tempos de tendências de supremacia cultural urbana. Não promover essa ação filosófica, no tocante à defesa ideológica do que o homem do campo deixou como legado, em uma projeção mais ampla, proporcionaria liberdade para o acontecimento de uma homogeneização cultural.

\section{CONCLUSÃO}

Ficou demonstrado ser possível obter o reconhecimento como patrimônio cultural imaterial por meio de lei, a partir do procedimento simples, sem sofisticação e complexidade que, envolveu basicamente: enquadrar a prática no conceito; buscar informações históricas; obter a anuência dos seus produtores e apresentar ao legislativo. Assim ficou comprovado que o que se almejava não precisaria ser necessariamente feito via IPHAN, era factível e proporcionaria valorização e destaque da tradição do Laço no cenário cultural rio-grandense e brasileiro, contribuindo, assim, para sua manutenção.

\section{NOTAS}

1. HORTA. Maria de Lourdes; GRUNBERG, Evelina; MONTEIRO, Adriane Queiroz. Guia Básico da Educação Patrimonial. IPHAN.

2. BRASIL. Decreto $n^{\circ}$ 3.551, de 04 de agosto de 2000. Institui o Registro de Bens Culturais de Natureza Imaterial que constituem patrimônio cultural brasileiro, cria o Programa Nacional do Patrimônio Imaterial e dá outras providências. Brasília, DF: Presidência da República. IPHAN.

3. Idem nota 2.

4. Idem

5. IPHAN. Decreto 3551, de 04 de agosto de 2000.

6. IPHAN. Resolução $n^{\circ}$ 001, de 03 de agosto de 2006.

7. JACQUES, João Cezimbra. Assuntos do Rio Grande do Sul, Porto Alegre: Officinas Graphicas da Escola de Engenharia, 1912,p. 60.

8. Idem, p. 59.

9. JACQUES, João Cezimbra. Assuntos do Rio Grande do Sul, Porto Alegre: Officinas Graphicas da Escola de Engenharia, 1912, p. 60.

10. MTG. Ofício, 406/2010. Porto Alegre. 08 de dezembro de 2010.

11. KARL DIEM apud TUBINO, Manoel. O Que é o esporte. São Paulo: Brasiliense, 1999. p. 12.

12. LESSA, Barbosa, OLIVEN, Ruben George. A Parte e o Todo. Petrópolis: Editora Vozes, 2006. p. 118. 
13. PORTAL IPHAN. Parecer $\mathbf{N}^{\circ}$ 031/208. Registro da Capoeira como Patrimônio Cultural do Brasil. Salvador: IPHAN, 2008. p.12.

14. PICCOLO et al. História Geral do Rio Grande do Sul, Colônia. v. 1. Passo Fundo: Ed. Méritos, 2006.

15. Idem.

16. WENDROTH, Hermann Rudoldf. 1852.

17. DREYS, Nicolau. Notícia Descriptiva da Província do Rio Grande de S. Pedro do Sul. Porto Alegre: Oficinas Gráficas da Livraria do Globo S. A, 1928.

18. DIÁRIO. Porto Alegre, 19 de setembro de 1912. Página 2. Grêmio Gaúcho. Museu de Comunicação Social Hipólito José da Costa.

19. BRITO, Severino Sá. Trabalhos e Costumes dos Gaúchos. Porto Alegre: Erus, 1928.

20. MTG. Anais do $47^{\circ}$ Congresso Tradicionalista. Porto Alegre: Evangraf, 2002.

21. COSTA, Luiz Carlos Bossle. Tiro de Laço de Forma Competitiva. Origem e Função Cultural do Rodeio Crioulo. 02 jan. 2002.

22. MTG. Anais do $47^{\circ}$ Congresso Tradicionalista. Porto Alegre: Evangraf, 2002.

23. JORNAL DO DIA. Porto Alegre, 05 de maio de 1963. Gaúchos autênticos cultuam a tradição através de competições Campeiras: Torneios de Laço. Igtf, Hemeroteca, Rodeio, 34.4.

24. LEMOS NETO, José Atanásio. Resumo da História Do Laço Comprido Como Esporte No Ms.

25. FEDERAÇÃO DE CLUBES DE LAÇO DO MATO GROSSO DO SUL. Estatuto. p. 6.

26. MATO GROSSO DO SUL. Lei № 2630, de 16 de junho de 2003.

27. PREFEITURA DE GLORINHA. Lei 714, de 08 de novembro de 2004. Institui o Tiro de Laço como modalidade esportiva oficial do Município de Glorinha, e dá outras providências. Glorinha: Prefeitura Municipal de Glorinha, 2004.

28. BRASIL. Lei 9.615, de 24 de março de 1998. Institui normas gerais sobre desporto e dá outras providências. Brasília, DF: Presidência da República, 1998.

29. BRASIL. Lei Federal 13.364/16.

30. RIO GRANDE DO SUL. Câmara dos Deputados. Projeto de Emenda Constitucional - PEC 304.

31. COSTELLA, Juvir. Projeto de Lei n. 144/2017. Declara como bem integrante do patrimô-nio cultural imaterial do Estado do Rio Grande do Sul e considera como atividade desporti-va a Prova de Laço, e dá outras providências. Rio Grande do Sul: Assembleia Legislativa do Rio Grande do Sul, 27 dez. 2018.

32. GRIZOTTI, Giovani. Gravataí quer tornar tiro de Laço patrimônio do país.

33. ABCCC presente na manifestação em favor dos esportes equestres. Associação Brasileira de Criadores de Cavalos Crioulos.

34. RIO GRANDE DO SUL. Lei Ordinária No 15.244, de 27 de dezembro de 2018. Declara como bem integrante do patrimônio cultural imaterial do Estado do Rio Grande do Sul e considera como atividade desportiva a Prova de Laço e dá outras providências. Porto Alegre: Palácio Piratini, 2018.

35. RIO GRANDE DO SUL. AL/RS. Comissões Permanentes.

36. COSTELLA, Juvir. Projeto de Lei n. 144/2017. Declara como bem integrante do patrimô-nio cultural imaterial do Estado do Rio Grande do Sul e considera como atividade desporti-va a Prova de Laço, e dá outras providências. Rio Grande do Sul: Assembleia Legislativa do Rio Grande do Sul, 27 dez. 2018. 
37. BRASIL. Decreto $\mathbf{n}^{\circ} \mathbf{3 . 5 5 1}$, de 04 de agosto de 2000. Institui o Registro de Bens Culturais de Natureza Imaterial que constituem patrimônio cultural brasileiro, cria o Programa Nacional do Patrimônio Imaterial e dá outras providências. Brasília, DF: Presidência da República. IPHAN.

\section{REFERÊNCIAS}

$A B C C C$ presente na manifestação em favor dos esportes equestres. Associação Brasileira de Criadores de Cavalos Crioulos. Disponível em: http://www.cavalocrioulo.org.br/noticias/detalhes/133554/abcccpresente-na-manifestacao-em-favor-dos-esportes-equestres. Acesso em: 21 maio 2019.

ASSEMBLEIA LEGISLATIVA DO MATO GROSSO DO SUL. Lei $\mathbf{N}^{\circ}$ 2630, de 16 de junho de 2003. Disponível em: http://aacpdappls.net.ms.gov.br/appls/legislacao/secoge/govato. nsf/448b683bce4ca84704256c0b00651e9d/423793e0df70c87004256d48004816b0?OpenDocument. Acesso em: 23 maio 2019.

BRASIL. Câmara dos Deputados. Projeto de Emenda Constitucional - PEC 304. Disponível em: https://www.google.com/ search?q=PEC+304\&oq=PEC+304\&aqs=chrome $.0 .69 i 59 j 015.4388$ j0j8\&sourceid=chrome\&ie=UTF-8. Acesso em: 23 maio 2019.

BRASIL. Decreto $n^{\circ}$ 3.551, de 04 de agosto de 2000. Institui o Registro de Bens Culturais de Natureza Imaterial que constituem patrimônio cultural brasileiro, cria o Programa Nacional do Patrimônio Imaterial e dá outras providências. Brasília, DF: Presidência da República. Disponível em: http://portal.iphan.gov.br/ uploads/ckfinder/arquivos/Decreto $\% 20$ n\%C2\%BA\%203_551\%20de $\% 2004 \% 20$ de $\% 20$ agosto $\% 20$ de $\% 20$ 2000.pdf. Acesso em: 23 maio 2019.

BRASIL. Lei 9.615, de 24 de março de 1998. Institui normas gerais sobre desporto e dá outras providências. Brasília, DF: Presidência da República, 1998. Disponível em: http://www.planalto.gov.br/ ccivil_03/leis/l9615consol.htm. Acesso em: 24 maio 2019.

BRASIL. Lei Federal 13.364/16. . Reconhece o rodeio, a vaquejada e o laço, bem como as respectivas expressões artísticas e esportivas, como manifestações culturais nacionais; eleva essas atividades à condição de bens de natureza imaterial integrantes do patrimônio cultural brasileiro; e dispõe sobre as modalidades esportivas equestres tradicionais e sobre a proteção ao bem-estar animal. Brasília, DF: Presidência da República, 2016. Disponível em: http://www.planalto.gov.br/ccivil_03/_ato2015-2018/2016/ lei/L13364.htm. Acesso em: 23 maio 2016.

BRITO, Severino Sá. Trabalhos e Costumes dos Gaúchos. Porto Alegre: Erus, 1928.

COSTA, Luiz Carlos Bossle. Tiro de Laço de Forma Competitiva. Origem e Função Cultural do Rodeio Crioulo. 02 jan. 2002.

COSTELLA, Juvir. Projeto de Lei n. 144/2017. Declara como bem integrante do patrimônio cultural imaterial do Estado do Rio Grande do Sul e considera como atividade desporti-va a Prova de Laço, e dá outras providências. Rio Grande do Sul: Assembleia Legislativa do Rio Grande do Sul, 27 dez. 2018. Disponível em: http://proweb.procergs.com.br/consulta_proposicao. asp?SiglaTipo=PL\&NroProposicao=144\&AnoProposicao=2017. Acesso em: 24 maio 2019.

DIÁRIO. Porto Alegre, 19 de setembro de 1912. p. 2. Grêmio Gaúcho. Museu de Comunicação Social Hipólito José da Costa. 
DREYS, Nicolau. Notícia Descriptiva da Província do Rio Grande de S. Pedro do Sul. Porto Alegre: Oficinas Gráficas da Livraria do Globo S. A. 1928.

FEDERAÇÃO DE CLUBES DE LAÇO DO MATO GROSSO DO SUL. Estatuto. Disponível em: https://static1.squarespace.com/static/5bf068c83e2d09d0f4e0a28d/t/5bf14bf9562fa782870e1f 6f/1542540283255/Estatutofederac\%CC\%A7a\%CC\%830+de+clubes+de+lac\%CC\%A7o+do+MS.pdf. Acesso em: 03 jun. 2019.

GRIZOTTI, Giovani. Gravataí quer tornar tiro de Laço patrimônio do país. Disponível em : http:/l g1.globo.com/rs/rio-grande-do-sul/reporter-farroupilha/platb/2013/06/17/gravatai-quer-tornar-tiro-de-lacopatrimonio-cultural/. Acesso em: 21 maio 2017.

HORTA, Maria de Lourdes; GRUNBERG, Evelina; MONTEIRO, Adriane Queiroz. Guia Básico da Educação Patrimonial. Disponível em: http://portal.iphan.gov.br/uploads/temp/guia_educacao_ patrimonial.pdf.pdf. Acesso em: 23 maio 2019.

JACQUES, João Cezimbra. Assuntos do Rio Grande do Sul. Porto Alegre: Officinas Graphicas da Escola de Engenharia, 1912.

JORNAL DO DIA. Porto Alegre, 05 de maio de 1963. Gaúchos autênticos cultuam a tradição através de competições Campeiras: Torneios de Laço. Igtf, Hemeroteca, Rodeio, 34.4.1963.

LEMOS NETO, José Atanásio. Resumo da História do Laço Comprido Como Esporte No Ms. Disponível em: http://www.meucavaloepantaneiro.com.br/laco_comprido.htm. Acesso em: 11 jul. 2007.

LESSA, Barbosa; OLIVEN, Ruben George. A Parte e o Todo. Petrópolis: Editora Vozes, 2006. p. 118.

MTG. Anais do $47^{\circ}$ Congresso Tradicionalista. Porto Alegre, Evangraf, 2002.

PORTAL IPHAN. Parecer No 031/208. Registro da Capoeira como Patrimônio Cultural do Brasil. Salvador: IPHAN, 2008. Disponivel em: http://portal.iphan.gov.br/uploads/ckfinder/arquivos/Parecer\%20Capoeira. pdf. Acesso em: 17 maio 2019.

PORTAL IPHAN. Presidente do Conselho Consultivo do Patrimônio Cultural. Resolução $\mathbf{n}^{\circ}$ 001, de 03 de agosto de 2006. Brasilia, DF: Presidente do Conselho Consultivo do Patrimônio Cultural, 2006. Disponível em: http://portal.iphan.gov.br/uploads/ckfinder/arquivos/Resolucao_001_de_3_de_agosto_ de_2006.pdf. Acesso em: 23 maio 2019.

PREFEITURA DE GLORINHA. Lei 714, de 08 de novembro de 2004. Institui o Tiro de Laço como modalidade esportiva oficial do Município de Glorinha, e dá outras providências. Glorinha: Prefeitura Municipal de Glorinha, 2004. Disponível em : http://www.glorinha.rs.gov.br/downloads/leis/2004/LEl.714. pdf. Acesso em: 23 maio 2019.

RIO GRANDE DO SUL. Lei Ordinária No 15.244, de 27 de dezembro de 2018. Declara como bem integrante do patrimônio cultural imaterial do Estado do Rio Grande do Sul e considera como atividade desportiva a Prova de Laço e dá outras providências. Porto Alegre: Palácio Piratini, 2018. Disponível em: http://leisestaduais.com.br/rs/lei-ordinaria-n-15244-2018-rio-grande-do-sul-declara-como-bemintegrante-do-patrimonio-cultural-imaterial-do-estado-do-rio-grande-do-sul-e-considera-como-atividadedesportiva-a-prova-de-laco-e-da-outras-providencias. Acesso em: 23 maio 2017.

RIO GRANDE DO SUL. AL/RS. Comissões Permanentes. Disponível em: http://www.al.rs.gov.br/ 
ALVES, Eduardo Fonseca; SÁ, Mário Antônio Taddei -Apresentação do processo de reconhecimento do Laço como esporte e patrimônio cultural imaterial, por meio de lei

legislativo/Comissoes.aspx?IdComissao=108. Acesso em: 21 maio 2019.

TUBINO, Manoel. O Que é o esporte. São Paulo: Brasiliense, 1999

Recebido em: 14/06/2019

Aceito em: 07/07/2019 